\title{
Prednisone inhibits the IL-1 $\beta$-induced expression of COX-2 in HEI-OC1 murine auditory cells through the inhibition of ERK-1/2, JNK-1 and AP-1 activity
}

\author{
HUA HONG ${ }^{1}$ and BYEONG-CHURL JANG \\ Department of Molecular Medicine, College of Medicine, \\ Keimyung University, Dalseo-gu, Daegu 704-701, Republic of Korea \\ Received April 18, 2014; Accepted October 1, 2014
}

DOI: $10.3892 /$ ijmm.2014.1967

\begin{abstract}
Hearing loss can be induced by multiple causes, including cochlear inflammation. Prednisone (PDN) is a well-known steroid clinically used in the treatment of hearing loss. In the present study, we investigated the inhibitory effects and the mechanisms of action of PDN on the expression of cyclooxygenase (COX)-2, an inflammatory enzyme involved in the production of prostaglandins (PGs), in House Ear InstituteOrgan of Corti 1 (HEI-OC1) cells (a murine auditory cell line) treated with the inflammatory cytokine, interleukin (IL)-1 $\beta$. The exposure of HEI-OC1 cells to IL- $1 \beta$ increased COX-2 protein and mRNA expression, COX-2 promoter-driven luciferase activity and COX-2 enzymatic activity [as indicated by the increased production of prostaglandin $\mathrm{E}_{2}\left(\mathrm{PGE}_{2}\right)$, a major COX-2 metabolite]. However, PDN markedly inhibited the IL-1 $\beta$-induced COX-2 protein and mRNA expression, COX-2 promoter activity and $\mathrm{PGE}_{2}$ production in the HEI-OC1 cells without affecting COX-2 protein and mRNA stability. PDN further inhibited the IL-1 $\beta$-induced activation of extracellular signal-regulated kinase (ERK)-1/2 and c-Jun N-terminal kinase (JNK)-1, but had no effect on the cytokine-induced activation of p38 MAPK and proteolysis of $\mathrm{I} \kappa \mathrm{B}-\alpha$, a nuclear factor- $\kappa \mathrm{B}$ $(\mathrm{NF}-\kappa \mathrm{B})$ inhibitory protein. PDN also partially suppressed the IL-1 $\beta$-induced activation of activator protein (AP)-1 (but not that of $\mathrm{NF}-\kappa \mathrm{B}$ ) promoter-driven luciferase activity. Of note, the inhibitory effects of PDN on the IL-1 $\beta$-induced expression of COX- 2 and the activation of ERK-1/2 and JNK-1 in the HEI-OC1
\end{abstract}

Correspondence to: Dr Byeong-Churl Jang, Department of Molecular Medicine, College of Medicine, Keimyung University, 1095 Dalgubeol-daero, Dalseo-gu, Daegu 704-701, Republic of Korea

E-mail: jangbc123@gw.kmu.ac.kr

Present address: ${ }^{1} \mathrm{CHA}$ Cancer Prevention Research Center, CHA Cancer Institute, Seoul 704-701, Republic of Korea

Key words: interleukin-1 $\beta$, cyclooxygenase-2, activating protein-1, extracellular signal-regulated kinase-1/2, c-Jun N-terminal kinase-1, House Ear Institute-Organ of Corti 1 cells cells were significantly diminished by RU486, a glucocorticoid receptor (GR) antagonist, suggesting that PDN exerts its inhibitory effects through GR. To the best of our knowledge, our study demonstrates for the first time that PDN inhibits the IL-1 $\beta$-induced COX-2 expression and activity in HEI-OC1 cells by COX-2 transcriptional repression, which is partly associated with the inhibition of ERK-1/2, JNK-1 and AP-1 activation.

\section{Introduction}

Hearing loss is the most common sensory impairment in humans, affecting $5 \%$ of individuals in industrialized nations $(1,2)$. Evidence strongly suggests that hearing loss is a serious health issue in the elderly and $40 \%$ of the population aged $>65$ years have a hearing loss severe enough to impair communication $(3,4)$. It has been suggested that hearing loss is induced by multiple causes, including infection/inflammation, noise and ototoxic drugs (4-7).

Cyclooxygenase (COX), also known as prostaglandin (PG) $\mathrm{H}$ synthase, is the rate-limiting enzyme in the biosynthesis of PGs from arachidonic acid (8). Physiologically, PGs are involved in inflammatory responses, bone development, wound healing and reproductive function. However, the excessive production of PGs is associated with many diseases, including inflammation, atherosclerosis, cardiovascular diseases and cancer (8-10). COX exists in two isoforms, COX-1 and COX-2 (11). COX-1 is constitutively expressed in most cell types and is thought to be involved in the maintenance of physiological functions, including the cytoprotection of the stomach, platelet aggregation and the regulation of renal blood flow. By contrast, COX-2 is inducible by inflammatory stimuli, such as interleukin (IL)-1 $\beta$, tumor necrosis factor- $\alpha$ (TNF- $\alpha$ ) and lipopolysaccharide (LPS) (8-12). The overexpression of COX-2 is closely associated with a number of inflammatory diseases (13). Of note, previous studies have indicated that COX-1 and COX-2 are expressed in the cochlea of humans and guinea pigs $(14,15)$. However, the regulatory mechanism of COX-2 expression in the cochlea remains unclear.

Glucocorticoids are the most effective anti-inflammatory drugs used in the treatment of inflammation-related diseases, including rheumatoid arthritis and asthma $(16,17)$. It has been demonstrated that glucocorticoids bind to the glucocorticoid 
receptor (GR) and negatively regulate the expression of several inflammatory mediators, including COX-2 and cytokines by inhibiting transcription factors, such as activator protein (AP)-1, nuclear factor- $\kappa \mathrm{B}(\mathrm{NF}-\kappa \mathrm{B})$, signal transducers and activators of transcription (STATs) and nuclear factor of activated $\mathrm{T}$ cells (NF-AT) (18-21). Among the glucocorticoids, prednisone $(\mathrm{PDN})$ is currently the most effective regimen clinically used in the treatment of hearing loss. However, little is known about the association between PDN and the regulation of COX-2 expression in the cochlea.

House Ear Institute-Organ of Corti 1 (HEI-OC1) cell is a murine auditory cell line that is widely used as an in vitro system for screening and/or evaluating the potential ototoxicity or otoprotective properties of pharmacological drugs (22). In the present study, we investigated the inhibitory effects and mechanisms of action of PDN on COX-2 expression in IL-1 $\beta$-stimulated HEI-OC1 cells.

\section{Materials and methods}

Cell lines and culture. The HEI-OC1 cells were purchased from the House Ear Institute (Los Angeles, CA, USA) and grown in DMEM without sodium pyruvate (Gibco, Carlsbad, CA, USA) supplemented with $10 \%$ heat-inactivated fetal bovine serum (FBS), $100 \mathrm{U} / \mathrm{ml}$ penicillin and $100 \mathrm{mg} / \mathrm{ml}$ streptomycin (all from Wellgene, Daegu, Korea) at $37^{\circ} \mathrm{C}$ in a humidified $5 \% \mathrm{CO}_{2}$ atmosphere.

Materials. Antibodies to phosphorylated (p-) extracellular signal-regulated kinase (ERK)-1/2, total (t-)ERK-1/2, p-c-Jun N-terminal kinase (JNK)-1/2, t-JNK-1/2, p-p38 mitogenactivated protein kinase (MAPK), t-p38 MAPK, p-protein kinase $\mathrm{B}(\mathrm{PKB}), \mathrm{t}-\mathrm{PKB}$ and $\mathrm{I} \kappa \mathrm{B}-\alpha$ were purchased from Cell Signaling Technology, Inc. (Beverly, MA, USA). An antiCOX-2 polyclonal antibody was purchased from Cayman Chemical Co. (Ann Arbor, MI, USA). An anti-actin antibody was obtained from Sigma-Aldrich (St. Louis, MO, USA). Antirabbit or mouse secondary horseradish peroxidase antibodies were obtained from Amersham Biosciences (Amersham, UK). Actinomycin D (Act D) and cycloheximide (CHX) were purchased from Sigma-Aldrich.

Preparation of whole cell lysates. Whole cell lysate was prepared in a modified RIPA buffer [50 mM Tris-Cl (pH 7.4), $150 \mathrm{mM} \mathrm{NaCl}, 1 \%$ Triton $\mathrm{X}-100,1 \%$ sodium deoxycholate, $1 \%$ Nonidet P-40, $1 \mathrm{mM} \mathrm{Na} \mathrm{VO}_{4}, 1 \mathrm{mM} \mathrm{NaF}, 1 \mathrm{mM}$ EDTA, $200 \mathrm{nM}$ aprotinin, $20 \mu \mathrm{M}$ leupeptin, $50 \mu \mathrm{M}$ phenanthroline and $280 \mu \mathrm{M}$ benzamidine-HCl]. For the detection of phosphorylated proteins, the cells were twice washed with ice-cold phosphate-buffered saline (PBS) supplemented with $1 \mathrm{mM} \mathrm{Na} \mathrm{VO}_{4}$ and $1 \mathrm{mM} \mathrm{NaF}$, and lysed in the modified RIPA buffer mentioned above. Following centrifugation at the lysed cell suspension at $12,000 \mathrm{rpm}$ for $20 \mathrm{~min}$ at $4^{\circ} \mathrm{C}$, the following supernatant was saved as whole cell lysate. The protein concentration of the whole cell lysate was measured using Bradford reagent (Bio-Rad Laboratories, Mississauga, ON, USA) using bovine serum albumin as the standard.

Western blot analysis. Equal amounts of protein (50 $\mu \mathrm{g} / \mathrm{lane})$ were resolved by $10 \%$ sodium dodecyl sulfate-polyacrylamide gel electrophoresis and transferred onto a nitrocellulose membrane (Millipore Co., Bedford, MA, USA). The membrane was then washed with Tris-buffered saline (TBS) $(10 \mathrm{mM}$ Tris, $150 \mathrm{mM} \mathrm{NaCl}$ ) containing $0.05 \%$ Tween-20 (TBST) and blocked in TBST supplemented with 5\% non-fat dried milk. The membrane was further incubated with the respective primary antibodies, p-ERK-1/2 (1:2,000), t-ERK-1/2 (1:2,000), p-JNK-1/2 (1:2,000), t-JNK-1/2 (1:2,000), p-p38 MAPK (1:2,000), t-p38 MAPK $(1: 2,000)$, p-PKB $(1: 2,000)$, t-PKB $(1: 2,000)$, IкB- $\alpha(1: 2,000)$, COX-2 $(1: 2,000)$ or $\beta$-actin $(1: 10,000)$. The membrane was subsequently incubated with appropriate secondary antibodies coupled to horseradish peroxidase and developed in enzyme-linked chemiluminescence (ECL) western blotting detection reagents (Amersham Pharmacia Biotech, Oakville, ON, USA).

Analysis of COX-2 protein stability. The HEI-OC1 cells were initially grown in the absence or presence of IL-1 $\beta$ for $8 \mathrm{~h}$ to highly induce endogenous COX-2 protein. The cells were then treated with IL-1 $\beta$ alone or IL-1 $\beta$ plus PDN for an additional 8 , 16 or $24 \mathrm{~h}$ in the presence of CHX, a translational inhibitor. At each time point, whole cell lysate was prepared and subjected to western blot analysis for COX-2 or actin to determine the amount of each protein remaining in the cells.

Reverse transcription-polymerase chain reaction (RT-PCR). Total RNA was isolated using TRIzol reagent (Invitrogen, Carlsbad, CA, USA) according to the instructions provided by the manufacturer. Five micrograms of total RNA were reverse transcribed using $8 \mu \mathrm{l}$ of M-MLV reverse transcription $5 \mathrm{X}$ buffer, $3 \mu \mathrm{l}$ of $10 \mathrm{mM}$ dNTPs, $0.45 \mu \mathrm{l}$ of 10,000 units (U) RNase inhibitor, $0.3 \mu \mathrm{l}$ of 50,000 U M-MLV reverse transcriptase (Promega, Madison, WI, USA) and $1.5 \mu \mathrm{l}$ of $50 \mathrm{pM}$ oligo(dT) (Bioneer, Chungbuk, Korea) in a $40 \mu \mathrm{l}$ volume. Single-stranded cDNA was then amplified by PCR using $4 \mu \mathrm{l}$ of $5 \mathrm{X}$ green GoTaq ${ }^{\circledR}$ flexi buffer, $0.4 \mu \mathrm{l}$ of $10 \mathrm{mM}$ dNTPs, $0.1 \mu \mathrm{l}$ of $500 \mathrm{U}$ Taq polymerase, $1.2 \mu \mathrm{l}$ of $25 \mathrm{mM} \mathrm{MgCl}_{2}$ (Promega) and $0.4 \mu \mathrm{l}$ of each $20 \mathrm{pM}$ of specific sense and antisense primer of COX-2 or glyceraldehyde-3-phosphate dehydrogenase (GAPDH). The primer sequences used for PCR were as follows: COX-2 forward, 5'-CTG TAC TAC GCC GAG ATT CCT GA-3' and reverse, 5'-GTC CTC GCT TCT GAT CTG TCT TG-3'; GAPDH forward, 5'-GGT GAA GGT CGG TGT GAA CG-3' and reverse, 5'-GGT AGG AAC ACG GAA GGC CA-3'. The PCR products were then analyzed on a $1.2 \%$ agarose gel.

Analysis of COX-2 mRNA stability. The HEI-OC1 cells were initially grown in the absence or presence of IL-1 $\beta$ for $8 \mathrm{~h}$ to highly induce endogenous COX-2 mRNA expression. The cells were then treated with IL-1 $\beta$ alone or IL-1 $\beta$ plus PDN for an additional 2, 4 or $8 \mathrm{~h}$ in the presence of Act $\mathrm{D}$, a transcriptional inhibitor, to block ongoing transcription for an additional 1 , 2,4 or $8 \mathrm{~h}$. At each time point, total RNA was isolated and subjected to RT-PCR for COX-2 or GAPDH to determine the amount of mRNA remaining in the cells.

Transfection and luciferase assay. The HEI-OC1 cells were seeded in 6-well plates the day prior to transfection at a concentration of $2 \times 10^{5}$ cells/plate in a $2 \mathrm{ml}$ volume. The cells were transfected with $1 \mu \mathrm{g}$ of the luciferase DNA construct 
containing the COX-2 promoter or $20 \mathrm{ng}$ of the Renilla luciferase expression vector control pRL-TK DNA (Promega) using Lipofectamine 2000 reagent (Invitrogen) according to the manufacturer's instructions. At $24 \mathrm{~h}$ post-transfection, the cells were grown for an additional $8 \mathrm{~h}$ in the absence or presence of PDN. The cells were then washed and lysed, followed by the measurement of luciferase activity using a Dual-Luciferase assay kit (Promega) and a luminometer Victor3 (product no: 1420-011; Perkin Elmer Medical Imaging, Santa Clara, CA, USA). The luciferase activity was normalized with expression of control pRL-TK.

Measurement of prostaglandin $E_{2}\left(P_{G} E_{2}\right)$ production. $\mathrm{PGE}_{2}$ production was measured using a $\mathrm{PGE}_{2}$ enzyme-linked immunosorbent assay (ELISA) kit (Amersham Biosciences). Briefly, $6 \times 10^{5}$ cells plated were initially serum starved for $24 \mathrm{~h}$ and were then treated with IL-1 $\beta$ alone or with IL- $1 \beta$ plus PDN at the indicated concentrations for $8 \mathrm{~h}$. The conditioned medium was collected and subjected to $\mathrm{PGE}_{2}$ ELISA assay in a 96-well plate according to the manufacturer's instructions. In principal, the product of this enzymatic reaction has a blue color that is absorbed at $450 \mathrm{~nm}$. The extent of the color is inversely proportional to the amount of free $\mathrm{PGE}_{2}$ present in the well during incubation.

Statistical analysis. The results are expressed as the means \pm standard error (SE), and the significance of differences between groups was determined by one-way ANOVA. Differences were considered statistically significant when the P-value was $<0.05$.

\section{Results}

$I L-1 \beta$ induces the expression of COX-2 through transcriptional upregulation in HEI-OCl cells. Initially, we investigated the effects of IL- $1 \beta$ on the protein expression of COX- 2 in the HEI-OC1 cells. Treatment with IL-1 $\beta$ at $5 \mathrm{ng} / \mathrm{ml}$ for $8 \mathrm{~h}$ increased COX-2 protein expression in the HEI-OC1 cells compared with the control (no IL-1 $\beta$ treatment) (Fig. 1A). RT-PCR was then performed to determine whether the protein expression of COX-2 induced by IL- $1 \beta$ was due to the increased transcription of COX-2. Treatment with IL- $1 \beta$ at $5 \mathrm{ng} / \mathrm{ml}$ for $8 \mathrm{~h}$ also increased the mRNA levels of COX-2 in the HEI-OC1 cells compared with the control (Fig. 1B). To determine the induction of COX-2 protein expression by IL- $1 \beta$ at the functional level, the effects of IL- $1 \beta$ on the production of $\mathrm{PGE}_{2}$, a major and stable COX-2 metabolite, in the IL- $1 \beta$-treated HEI-OC1 cells was also determined. Compared with the control, treatment with IL-1 $\beta$ at $5 \mathrm{ng} / \mathrm{ml}$ for $8 \mathrm{~h}$ led to marked increase in the production of $\mathrm{PGE}_{2}$, indicating that COX-2 was enzymatically active. Luciferase transfection experiments were then performed to determine the effects of IL- $1 \beta$ on COX-2 promoter activity in the HEI-OCl cells. Treatment with IL-1 $\beta$ stimulated the COX-2 promoter-driven luciferase expression in the HEI-OC1 cells (Fig. 1D).

$P D N$ inhibits $I L-1 \beta$-induced COX-2 expression and $P G E_{2}$ production in $\mathrm{HEI}-\mathrm{OCl}$ cells. We then determined whether PDN inhibits the IL-1 $\beta$-induced COX-2 expression and activity in the HEI-OC1 cells. Treatment with PDN suppressed the protein and
A

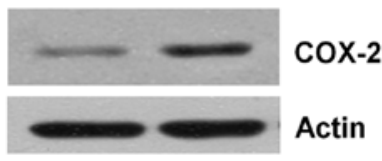

B
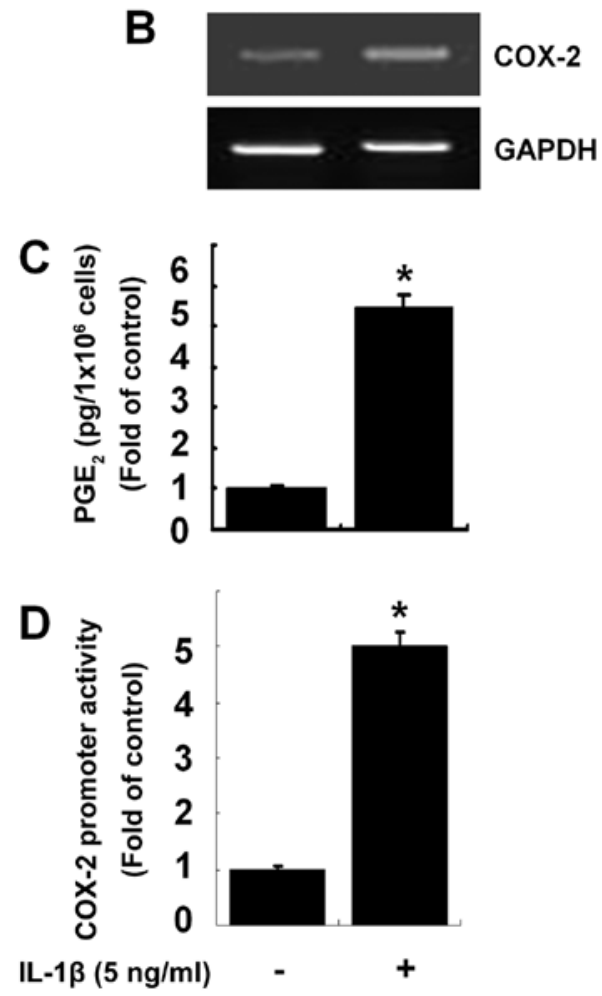

Figure 1. Effects of interleukin (IL)-1 $\beta$ on cyclooxygenase (COX)-2 expression and activity in House Ear Institute-Organ of Corti 1 (HEI-OC1) cells. (A and B) HEI-OC1 cells were serum-starved for $24 \mathrm{~h}$, and then treated with or without IL-1 $\beta$ for $8 \mathrm{~h}$. Whole cell lysates and total RNA were prepared and subjected to (A) western blot analysis and (B) RT-PCR, respectively. Each blot in (A) and (B) is representative of 3 independent experiments. (C) HEI-OC1 cells were serum-starved for $24 \mathrm{~h}$ and were then treated with or without IL-1 $\beta$ for $8 \mathrm{~h}$. The conditioned culture medium was collected and subjected to enzyme-linked immunosorbent assay (ELISA) for $\mathrm{PGE}_{2}$ production. Data are the means \pm SE from 3 independent experiments with 3 replicates. ${ }^{*} \mathrm{P}<0.05$ compared to the values of the control. (D) HEI-OC1 cells were co-transfected with $1 \mu \mathrm{g}$ of the rat COX-2 promoter-containing luciferase DNA along with $20 \mathrm{ng}$ of control pRL-TK DNA for $24 \mathrm{~h}$. The transfected cells were then treated with or without IL-1 $\beta$ for $8 \mathrm{~h}$. Whole cell lysates were prepared and used for the reporter gene activity. Data are the means \pm SE of 3 independent experiments. ${ }^{*} \mathrm{P}<0.05$ compared to the values of the control.

mRNA expression of COX-2 induced by IL-1 $\beta$ in a concentration-dependent manner (Fig. 2A and B), as well as the production of $\mathrm{PGE}_{2}$ (Fig. 2C) in the HEI-OC1 cells. Treatment with PDN at the dose of $10 \mu \mathrm{M}$ was sufficient to suppress the IL-1 $\beta$-induced expression and activity of COX-2. Treatment with PDN at $10 \mu \mathrm{M}$ also markedly suppressed the COX-2 promoter-driven luciferase expression induced by IL-1 $\beta$ in the HEI-OC1 cells (Fig. 2D).

PDN does not affect COX-2 protein and mRNA stability in IL-1 $\beta$-treated HEI-OCl cells. COX-2 expression is also regulated by protein turnover (35). This promptly led us to investigate whether PDN affects the stability of COX-2 protein in the IL-1 $\beta$-treated HEI-OC1 cells. As shown in Fig. 3A, the HEI-OC1 cells were initially treated with IL-1 $\beta$ (lanes 2-8) or without IL-1 $\beta$ (lane 1 ) for $6 \mathrm{~h}$ to induce the protein expression of COX-2. After $6 \mathrm{~h}$, the cells (lanes 1 and 2) were subjected to 


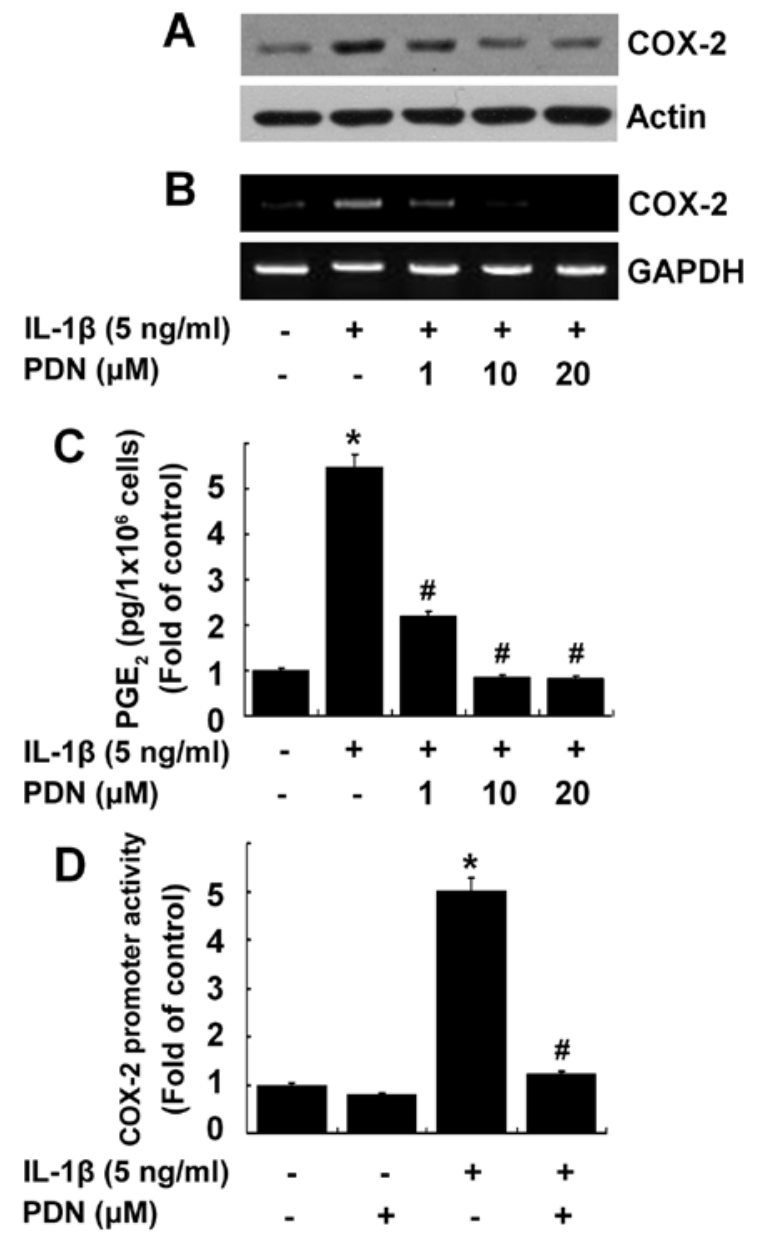

Figure 2. Effects of prednisone (PDN) on the interleukin (IL)-1 $\beta$-induced expression and activity of cyclooxygenase (COX)-2 in House Ear InstituteOrgan of Corti 1 (HEI-OC1) cells. (A and B) HEI-OC1 cells were serum-starved for $24 \mathrm{~h}$ and were then treated with or without IL-1 $\beta$ in the absence or presence of PDN at the indicated doses for $8 \mathrm{~h}$. Whole cell lysates and total RNA were prepared, and subjected to (A) western blot analysis and (B) RT-PCR, respectively. Each blot in (A) and (B) is representative of 3 independent experiments. (C) HEI-OC1 cells were serum-starved for $24 \mathrm{~h}$, and then treated with or without IL-1 $\beta$ in the absence or presence of PDN at the indicated doses for $8 \mathrm{~h}$. The conditioned culture medium was collected, and subjected to enzyme-linked immunosorbent assay (ELISA) for $\mathrm{PGE}_{2}$ production. Data are the means $\pm \mathrm{SE}$ from 3 independent experiments with 3 replicates. ${ }^{*} \mathrm{P}<0.05$ compared to the values of the control (no IL-1 $\beta$ treatment). ${ }^{~} \mathrm{P}<0.05$ compared to the values of treatment IL- $1 \beta$ without PDN (D) HEI-OC1 cells were co-transfected with $1 \mu \mathrm{g}$ of the rat COX-2 promotercontaining luciferase DNA along with 20 ng of control pRL-TK DNA for $24 \mathrm{~h}$. The transfected cells were then treated with or without IL-1 $\beta$ in the absence or presence of PDN for $8 \mathrm{~h}$. Whole cell lysates were prepared, and used for the reporter gene activity. Data are the means $\pm \mathrm{SE}$ of 3 independent experiments. ${ }^{*} \mathrm{P}<0.05$ compared to the values of the control ${ }^{\#} \mathrm{P}<0.05$ compared to the values of treatment IL-1 $\beta$ without PDN.

total cell lysate extraction (indicated as the $0 \mathrm{~h}$ time point). The remaining cells (lanes 3-8) were then exposed to IL-1 $\beta$ with or without PDN in the presence of $\mathrm{CHX}$, a translational inhibitor, for an additional 8,16 or $24 \mathrm{~h}$, following the preparation of total cell lysates at each time point. When ongoing translation was blocked by $\mathrm{CHX}$, there was no change in the protein levels of COX-2 in the IL-1 $\beta$-treated HEI-OC1 cells in the absence or presence of PDN, suggesting that PDN does not affect COX-2 protein stability in the IL-1 $\beta$-treated HEI-OC1 cells. The protein expression of actin was not affected in the HEI-OC1
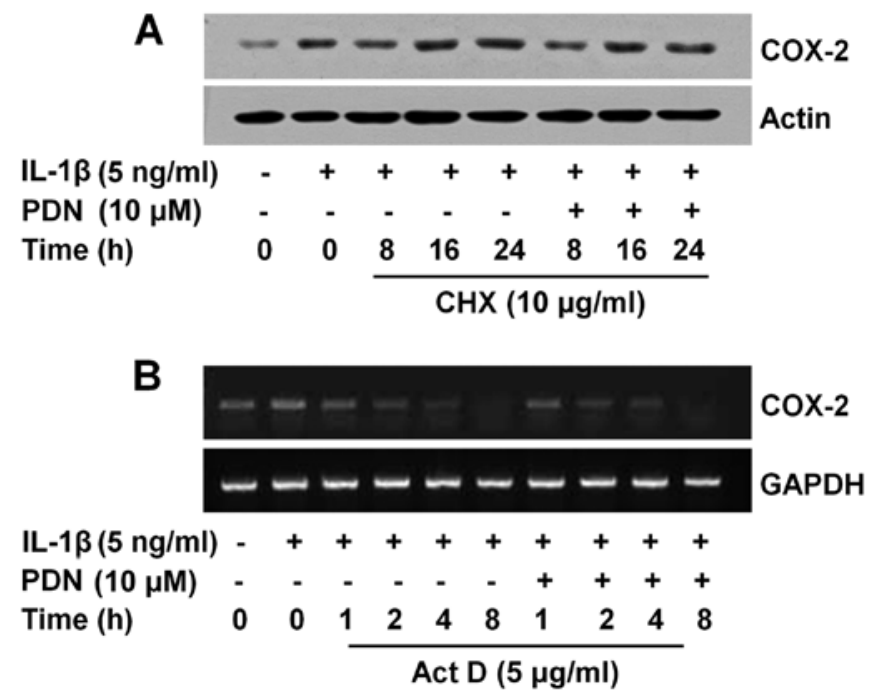

Figure 3. Effects of prednisone (PDN) on the stability of cyclooxygenase (COX)-2 protein and mRNA in interleukin (IL)-1 $\beta$-treated House Ear Institute-Organ of Corti 1 (HEI-OC1) cells. (A) HEI-OC1 cells were serumstarved for $24 \mathrm{~h}$, and then treated with (lanes 2-8) or without (lane 1) IL-1 $\beta$ for $8 \mathrm{~h}$ to highly induce COX-2 protein expression. HEI-OC1 cells were further exposed to IL-1 $\beta$ with (lanes 6-8) or without (lanes 3-5) or with PDN in the presence of cycloheximide ( $\mathrm{CHX}$ ), a translational inhibitor, for an additional 8,16 or $24 \mathrm{~h}$. At each time point, whole cell lysates were prepared and analyzed by western blot analysis. Each blot is representative of 3 independent experiments. (B) HEI-OC1 cells were serum-starved for $24 \mathrm{~h}$ and were then treated with (lanes 2-10) or without (lane 1) IL-1 $\beta$ for $8 \mathrm{~h}$ to highly induce COX-2 mRNA expression. HEI-OC1 cells were further exposed to IL-1 $\beta$ with (lanes 7-10) or without (lanes 3-6) PDN in the presence of actinomycin D (Act D), a transcriptional inhibitor, for an additional 1, 2, 4 or $8 \mathrm{~h}$. At each time point, total RNA was prepared and analyzed by RT-PCR. Each blot is representative of 3 independent experiments.

cells treated with or without IL-1 $\beta$ in the absence or presence of PDN at the indicated doses and for the indicated periods of time (Fig. 3A and B, lanes 1-8). COX-2 expression is also controlled by the COX-2 mRNA turnover $(35,42,43)$. When ongoing transcription was blocked by Act $\mathrm{D}$, a transcriptional inhibitor, there was no difference in the COX-2 mRNA levels in the IL-1 $\beta$-treated HEI-OC1 cells either in the absence or presence of PDN (Fig. 3B), indicating that PDN had no effect on COX-2 mRNA stability in the IL-1 $\beta$-treated cells. The mRNA expression of GAPDH remained constant in the HEI-OC1 cells treated without or with IL-1 $\beta$ in the absence or presence of $\mathrm{PDN}$ at the indicated doses and for the indicated periods of time (Fig. 3B, lanes 1-10).

PDN selectively blocks the IL-1 $\beta$-induced activation of ERK-1/2, JNK-1 and AP-1 in HEI-OCl cells. We then determined whether PDN affects the activation of intracellular signaling proteins, herein the family of MAPKs (ERK-1/2, JNK-1/2 and p38 MAPK), PKB and the NF- $\kappa$ B transcription factor in the IL-1 $\beta$-treated HEI-OC1 cells. The activation of the MAPK family, PKB and NF- $\kappa$ B by IL- $1 \beta$ was assessed by measuring the phosphorylation levels of ERK-1/2, JNK-1/2, p38 MAPK or PKB and the proteolysis of IкB- $\alpha$ (an inhibitor of $\mathrm{NF}-\kappa \mathrm{B}$ activation). As shown in Fig. 4A, compared with the control (no treatment; lane 1), the exposure of HEI-OC1 cells to IL-1 $\beta$ increased the phosphorylation levels of ERK-1/2, JNK-1, p38 MAPK and PKB, and induced the proteolysis of 

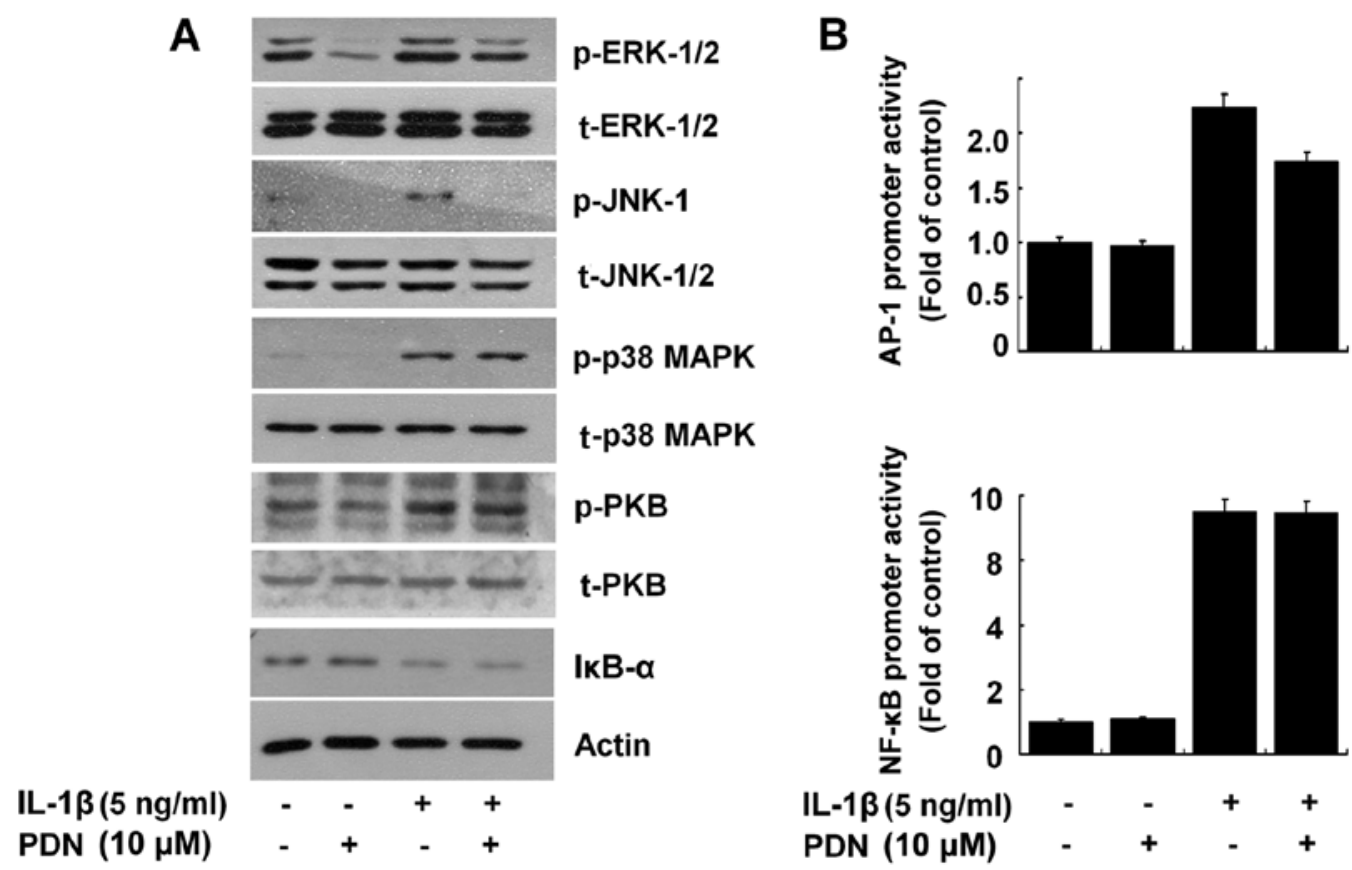

Figure 4. Effects of prednisone (PDN) on the expression and/or activity of signaling proteins and transcription factors in interleukin (IL)-1 $1 \beta$-treated House Ear Institute-Organ of Corti 1 (HEI-OC1) cells. (A) HEI-OC1 cells were serum-starved for $24 \mathrm{~h}$, and were then treated with or without PDN for $1 \mathrm{~h}$. HEI-OC1 cells were then treated with or without IL-1 $\beta$ in the absence or presence of PDN for an additional $0.5 \mathrm{~h}$. Whole cell lysates were prepared and analyzed by western blot analysis. p-ERK-1/2, phosphorylated ERK-1/2; t-ERK-1/2, total ERK-1/2; p-JNK-1/2, phosphorylated JNK-1/2; t-JNK-1/2, total JNK-1/2; p-p38 MAPK, phosphorylated p38 MAPK; t-p38 MAPK, total p38 MAPK; p-PKB, phosphorylated PKB; t-PKB, total PKB. Each blot is representative of 3 independent experiments. (B) HEI-OC1 cells were co-transfected with $1 \mu \mathrm{g}$ of the rat activator protein (AP)-1 or nuclear factor- $\mathrm{\kappa B}$ (NF- $\mathrm{kB}$ ) responsive element-containing luciferase DNA along with $20 \mathrm{ng}$ of control pRL-TK DNA for $24 \mathrm{~h}$. The transfected cells were then treated with or without IL-1 $\beta$ in the absence or presence of PDN for an additional $8 \mathrm{~h}$. Whole cell lysates were prepared and used for the reporter gene activity. Data are the means \pm SE of 3 independent experiments.

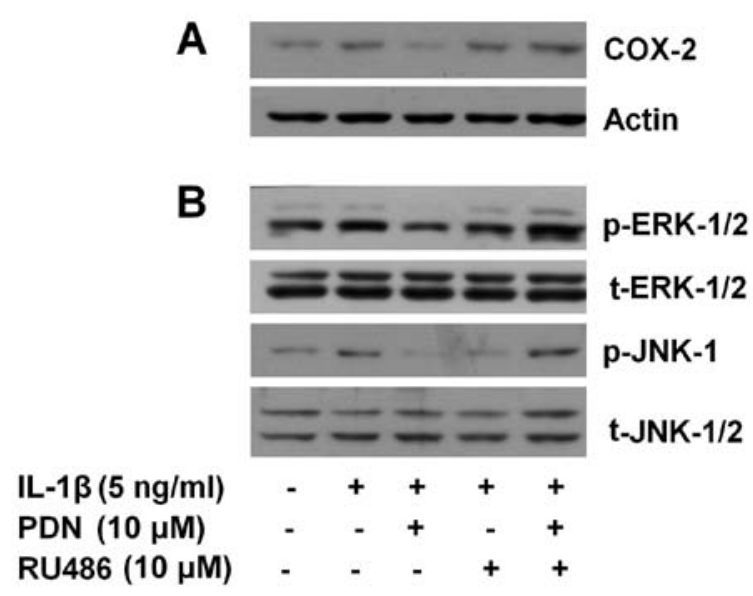

Figure 5. Effects of prednisone (PDN) and/or RU486 on the interleukin (IL)$1 \beta$-induced expression and/or activation of cyclooxygenase (COX)-2, ERK-1/2 and JNK-1. (A and B) House Ear Institute-Organ of Corti 1 (HEI-OC1) cells were serum-starved for $24 \mathrm{~h}$, and were then treated with or without RU486, an antagonist of glucocorticoid receptor for $1 \mathrm{~h}$. HEI-OC1 cells were also treated for $1 \mathrm{~h}$ with or without PDN in the absence or presence of RU486. HEI-OC1 cells were then treated with or without IL-1 $\beta$ in the absence or presence of PDN and/or RU486 for an additional (A) $8 \mathrm{~h}$ or (B) $0.5 \mathrm{~h}$. Whole cell lysates were prepared and analyzed by western blot analysis for (A) COX-2 or actin protein expression and (B) p-ERK-1/2, T-ERK-1/2, p-JNK-1/2 or T-JNK-1/2 expression. Each blot in $(\mathrm{A})$ or $(\mathrm{B})$ is representative of 3 independent experiments.

I $\kappa$ B- $\alpha$ (lane 3$)$. Notably, PDN inhibited the IL-1 $\beta$-induced phosphorylation of ERK-1/2 and JNK-1, but did not affect the IL-1 $\beta$-induced phosphorylation of PKB and the proteolysis of
I $\mathrm{B}-\alpha$ in the HEI-OC1 cells (Fig. 4A, lane 4). The total expression levels of ERK-1/2, JNK-1/2, p38 MAPK, PKB and actin remained largely unaffected in the HEI-OC1 cells treated without or with IL-1 $\beta$ in the absence or presence of PDN. Subsequent luciferase experiments revealed that PDN partially suppressed the AP-1 promoter-driven luciferase expression, but not the $\mathrm{NF}-\kappa \mathrm{B}$ promoter-driven luciferase expression induced by IL-1 $\beta$ in the HEI-OC1 cells (Fig. 4B).

RU486 attenuates the inhibitory effects of PDN on the $I L-1 \beta$-induced expression of COX-2 and activation of ERK-1/2 and JNK-1 in HEI-OC1 cells. Glucocorticoids bind to and act through the GR. RU486 is an antagonist of GR (37). Using RU486, we then determined whether PDN exerts its inhibitory effects on the IL-1 $\beta$-induced expression of COX-2 and the activation of ERK-1/2 and JNK- 1 in the IL-1 $\beta$-treated HEI-OC1 cells through GR. As anticipated, the IL-1 $\beta$-induced expression of COX-2 and the activation of ERK-1/2 and JNK-1 in the HEI-OC1 cells (Fig. 5, lane 2) was largely suppressed by PDN (Fig. 5, lane 3). In the absence of PDN, pre-treatment with RU486 did not affect the IL-1 $\beta$-induced expression of COX-2 and the activation of ERK-1/2 and JNK-1 in the HEI-OC1 cells (Fig. 5, lane 4). However, the suppressive effects of PDN on the IL-1 $\beta$-induced expression of COX-2 and the activation of ERK-1/2 and JNK-1 in the HEI-OC1 cells were not evident following pre-treatment with RU486 (Fig. 5, lane 5). The total expression levels of ERK-1/2, JNK-1/2 and actin remained constant in the HEI-OC1 cells treated with or without IL- $1 \beta$ in the absence or presence of PDN and/or RU486. 


\section{Discussion}

Existing evidence suggests a causative role of cochlear inflammation in the development of hearing loss. Little is known about the regulation of COX-2 gene expression by IL-1 $\beta$, a pro-inflammatory cytokine, and/or PDN, a well known steroid clinically used in the treatment of hearing loss $(5,6)$. In the present study, we investigated the effects of IL- $1 \beta$ and/or PDN on COX-2 expression in HEI-OC1 murine cochlear cells. To the best of our knowledge, this is the first study to demonstrate that IL-1 $\beta$ induces COX-2 expression through transcriptional upregulation, while PDN inhibits the IL- $1 \beta$-induced COX-2 expression through GR by transcriptional downregulation. Moreover, we provide evidence that PDN selectively blocks IL- $1 \beta$ signaling to activate ERK-1/2, JNK-1 and AP-1, which contributes to the transcriptional downregulation of COX-2.

It has been reported that an inflammatory response occurs in the inner ear under ear-damaging conditions, such as bacterial infection or noise overstimulation (23). In a previous study, it was demonstrated that the expression of pro-inflammatory cytokines, including IL-1, IL- 6 and TNF- $\alpha$, is increased in Haemophilus Influenzae-injected mice with acute otitis media (24), suggesting that these cytokines play a role in cochlear inflammation. In this study, we demonstrated that the exposure of HEI-OC1 cells to IL-1 $\beta$ upregulated the protein expression of COX-2 (Fig. 1A), which was attributed to increased COX-2 transcription (Fig. 1B) and promoter activity (Fig. 1D); we also demonstrated the IL-1 $\beta$-induced COX-2 protein at the functional level (Fig. 1C), as assessed by the high production of $\mathrm{PGE}_{2}$ in the HEI-OC 1 cells. It is likely that IL- $1 \beta$ plays a role in cochlear inflammation by producing inflammatory mediators, such as COX-2 and $\mathrm{PGE}_{2}$, while PDN may reduce the cochlear inflammatory response and/or the mediators triggered by the cytokine.

The regulation of COX-2 gene expression is primarily controlled at the transcriptional level. Earlier studies have shown that the COX-2 transcriptional induction is largely dependent on the activities of several transcription factors, which cognately bind to $c i s$-acting elements, including NF- $\mathrm{\kappa B}$, AP-1, cyclic AMP response element (CRE) or NF-IL6, within the COX-2 promoter (25-27). Among these, NF- $\kappa B$ is a redoxsensitive transcription factor and its activation is closely linked to the rapid proteolytic degradation of I $\kappa \mathrm{B}-\alpha$, a NF- $\kappa \mathrm{B}$ inhibitory protein (28). The rapid degradation of IkB- $\alpha$ unmasks the nuclear localization signals of NF- $\kappa \mathrm{B}$, which then translocates to the nucleus and activates the transcription of multiple genes, including COX-2. Ample evidence indicates that NF- $\mathrm{kB}$ activation is important for COX-2 transcriptional upregulation in response to extracellular stimuli $(27,29,30)$. AP-1 is another transcription factor that binds to AP-1 cis-acting element and stimulates COX-2 transcription (31), and its activation is largely dependent on the activity of upstream signaling effectors, such as ERK-1/2 and JNK-1/2 $(32,33)$. It has been demonstrated that treatment with IL-1 $\beta$ induces the phosphorylation of MAPKs (ERK-1/2, JNK-1/2 and p38 MAPK) and the I $\mathrm{B}$ - $\alpha$ proteolysisdependent activation of NF- $\mathrm{\kappa B}$, and their activation is critical for the cytokine-mediated induction of COX-2 expression in various types of cells $(29-31,34,35)$. Of note, has also been demonstrated that treatment with IL-1 $\beta(1 \mathrm{ng} / \mathrm{ml})$ for $15 \mathrm{~min}$ increases the phosphorylation of ERK-1/2 and JNK-1/2, but not that of p38 MAPK in HEI-OC1 cells (36). In this study, we demonstrated that treatment with IL-1 $\beta(5 \mathrm{ng} / \mathrm{ml})$ for $30 \mathrm{~min}$ induced not only the phosphorylation of ERK-1/2, JNK-1/2 and p38 MAPK but also the proteolysis of IкB- $\alpha$ in the HEI-OC1 cells (Fig. 4A). Furthermore, it was demonstrated that treatment with IL-1 $\beta$ induced the AP-1 or NF- $\mathrm{kB}$ promoter-driven luciferase expression in the HEI-OC1 cells (Fig. 4B). These results therefore suggest that treatment with IL- $1 \beta$ rapidly triggers the ERK-1/2- and JNK-1-dependent activation of AP-1, as well as I $\kappa \mathrm{B}-\alpha$ proteolysis-dependent NF- $\kappa \mathrm{B}$ activation in the HEI-OC1 cells, which contribute to $\mathrm{COX}-2$ transcriptional upregulation.

Glucocorticoids are among the most widely used drugs worldwide and are effective in a number of inflammatory and immune diseases (37). A major factor contributing to the anti-inflammatory action of glucocorticoids is the suppression of the expression and/or production of inflammatory mediators (38). PDN, a glucocorticoid agonist, has been shown to be an effective treatment for several inner ear disorders, including sudden idiopathic sensorineural hearing loss (39). At present, however, the PDN regulation of the cytokine-induced inflammatory response and signal transduction in cochlear cells is not well understood. In the present study, we demonstrated the ability of PDN to interfere with IL- $1 \beta$ signaling to induce the activation of ERK-1/2, JNK-1 and AP-1 without affecting the phosphorylation of p38 MAPK, the proteolysis of IкB- $\alpha$ and the activation of NF- $\kappa B$ in the HEI-OC1 cells (Fig. 4), suggesting that PDN selectively blocks these signaling components activated by IL-1 $\beta$ in the cells. Considering that the activity of ERK-1/2, JNK-1/2 and AP-1 is important for COX-2 expression $(30,31,34)$, it is likely that suppressive effects of PDN on the IL-1 $\beta$-induced expression of COX-2 in HEI-OC1 cells is through the inhibition of ERK-1/2, JNK-1 and AP-1 activity. Glucocorticoids act by binding to GR and subsequently translocating to the nucleus where they either increase (transactivate) or decrease (transrepress) target gene expression $(18,40,41)$. In this study, we demonstrated that the inhibitory effects of PDN on the IL-1 $\beta$-induced COX-2 expression and the activation of ERK-1/2 and JNK-1 in HEI-OC1 cells were largely diminished by pre-treatment with RU486, a GR antagonist (Fig. 5B). These results strongly suggest that PDN, through GR, abrogates IL- $1 \beta$ signal transduction leading to COX-2 expression and the activation of ERK-1/2, JNK-1 and AP-1 in the HEI-OC1 cells.

We, as well as others have previously reported that COX-2 expression is regulated at the post-transcriptional (mRNA stability) and/or translational (protein turnover) levels $(35,42-44)$. In the present study, however, experiments using Act D and CHX revealed that PDN did not affect the mRNA and protein stability of COX-2 in the IL- $1 \beta$-treated HEI-OC1 cells (Fig. 3), further stressing that the inhibitory effects of PDN on IL-1 $\beta$-induced COX-2 expression occur through transcriptional downregulation.

In conclusion, to the best of our knowledge, this is the first study to demonstrate that IL- $1 \beta$ induces the high expression of functional COX-2 through COX-2 transcriptional upregulation and the activation of ERK-1/2, JNK-1, p38 MAPK and NF- $\mathrm{KB}$, whereas PDN inhibits the cytokine-induced COX-2 expression through GR-dependent COX-2 transcriptional downregulation and the inhibition of ERK-1/2, JNK-1 and AP-1 activity in HEI-OC1 cells. The findings presented herein provide insight 
into the molecular basis of the beneficial effects of PDN against cochlear inflammation-related hearing loss.

\section{Acknowledgements}

This study was supported by the research promotion grant from the Keimyung University Dongsan Medical Center in 2008.

\section{References}

1. World Health Organization: Epidemic meningococcal disease. WHO fact sheet No. 105, 1998.

2. Schuchat A, Robinson K, Wenger JD, et al: Bacterial meningitis in the United States in 1995. Active Surveillance Team. N Engl J Med 337: 970-976, 1997.

3. Davis AC: Epidemiological profile of hearing impairments: the scale and nature of the problem with special reference to the elderly. Acta Otolaryngol Suppl 476: 23-31, 1990.

4. Ries PW: Prevalence and characteristics of persons with hearing trouble: United States, 1990-91. Vital Health Stat 188: 1-75, 1994.

5. Satoh H, Firestein GS, Billings PB, Harris JP and Keithley EM: Proinflammatory cytokine expression in the endolymphatic sac during inner ear inflammation. J Assoc Res Otolaryngol 4: 139-147, 2003.

6. Wakabayashi K, Fujioka M, Kanzaki S, et al: Blockade of interleukin-6 signaling suppressed cochlear inflammatory response and improved hearing impairment in noise-damaged mice cochlea. Neurosci Res 66: 345-352, 2010.

7. Matz G: Aminoglycoside cochlear ototoxicity. Otolaryngol Clin North Am 26: 705-712, 1993.

8. Smith WL, DeWitt DL and Garavito RM: Cyclooxygenases: structural, cellular, and molecular biology. Annu Rev Biochem 69: 145-182, 2000.

9. Smith WL and DeWitt DL: Prostaglandin endoperoxide $\mathrm{H}$ synthases-1 and -2. Adv Immunol 62: 167-215, 1996.

10. Vane JR, Bakhle YS and Botting RM: Cyclooxygenases 1 and 2. Annu Rev Pharmacol Toxicol 38: 97-120, 1998.

11. Feng L, Sun W, Xia Y, et al: Cloning two isoforms of rat cyclooxygenase: differential regulation of their expression. Arch Biochem Biophys 307: 361-368, 1993.

12. Cho JW, Park K, Kweon GR, et al: Curcumin inhibits the expression of COX-2 in UVB-irradiated human keratinocytes (HaCaT) by inhibiting activation of AP-1: p38 MAP kinase and JNK as potential upstream targets. Exp Mol Med 37: 186-192, 2005.

13. Dubois RN, Abramson SB, Crofford L, Gupta RA, Simon LS, Van De Putte LB and Lipsky P: Cyclooxygenase in biology and disease. FASEB J 12: 1063-1073, 1998.

14. Stjernschantz J, Wentzel P and Rask-Andersen H: Localization of prostanoid receptors and cyclo-oxygenase enzymes in guinea pig and human cochlea. Hear Res 197: 65-73, 2004.

15. Ziegler EA, Brieger J, Heinrich UR and Mann WJ: Immuno-histochemical localization of cyclooxygenase isoforms in the organ of Corti and the spiral ganglion cells of guinea pig cochlea. ORL J Otorhinolaryngol Relat Spec 66: 297-301, 2004.

16. Malysheva OA, Wahle M, Wagner U, Pierer M, Arnold S, Häntzschel $\mathrm{H}$ and Baerwald CG: Low-dose prednisolone in rheumatoid arthritis: adverse effects of various disease modifying antirheumatic drugs. J Rheumatol 35: 979-985, 2008.

17. Barnes PJ and Adcock IM: How do corticosteroids work in asthma? Ann Intern Med 139: 359-370, 2003.

18. Scheinman RI, Gualberto A, Jewell CM, Cidlowski JA and Baldwin AS Jr: Characterization of mechanisms involved in transrepression of NF-kappa B by activated glucocorticoid receptors. Mol Cell Biol 15: 943-953, 1995.

19. De Bosscher K, Beck IM, Dejager L, et al: Selective modulation of the glucocorticoid receptor can distinguish between transrepression of NF-кB and AP-1. Cell Mol Life Sci 71: 143-163, 2014.

20. Langlais D, Couture C, Balsalobre A and Drouin J: The Stat3/GR interaction code: predictive value of direct/indirect DNA recruitment for transcription outcome. Mol Cell 47: 38-49, 2012.

21. Adcock IM: Glucocorticoid-regulated transcription factors. Pulm Pharmacol Ther 14: 211-219, 2001.

22. Kalinec GM, Webster P, Lim DJ and Kalinec F: A cochlear cell line as an in vitro system for drug ototoxicity screening. Audiol Neurootol 8: 177-189, 2003.
23. Fujioka M, Kanzaki S, Okano HJ, Masuda M, Ogawa K and Okano H: Proinflammatory cytokines expression in noise-induced damaged cochlea. J Neurosci Res 83: 575-583, 2006.

24. Ghaheri BA, Kempton JB, Pillers DA and Trune DR: Cochlear cytokine gene expression in murine acute otitis media. Laryngoscope 117: 22-29, 2007.

25. Herschman HR, Reddy ST and Xie W: Function and regulation of prostaglandin synthase-2. Adv Exp Med Biol 407: 61-66, 1997.

26. Inoue $\mathrm{H}$, Yokoyama $\mathrm{C}$, Hara $\mathrm{S}$, Tone $\mathrm{Y}$ and Tanabe $\mathrm{T}$ : Transcriptional regulation of human prostaglandin-endoperoxide synthase-2 gene by lipopolysaccharide and phorbol ester in vascular endothelial cells. Involvement of both nuclear factor for interleukin-6 expression site and cAMP response element. J Biol Chem 270: 24965-24971, 1995 .

27. Inoue $\mathrm{H}$ and Tanabe $\mathrm{T}$ : Transcriptional role of the nuclear factor kappa B site in the induction by lipopolysaccharide and suppression by dexamethasone of cyclooxygenase-2 in U937 cells. Biochem Biophys Res Commun 244: 143-148, 1998.

28. Ghosh S and Baltimore D: Activation in vitro of NF-kappa B by phosphorylation of its inhibitor I kappa B. Nature 344: 678-682, 1990.

29. Newton R, Kuitert LM, Bergmann M, Adcock IM and Barnes PJ: Evidence for involvement of NF-kappaB in the transcriptional control of COX-2 gene expression by IL-1beta. Biochem and Biophys Res Commun 237: 28-32, 1997.

30. Jang BC, Paik JH, Kim SP, et al: Catalase induced expression of inflammatory mediators via activation of NF- $\kappa \mathrm{B}, \mathrm{PI} 3 \mathrm{~K} / \mathrm{AKT}$, p70S6K, and JNKs in BV2 microglia. Cell Signal 17: 625-633, 2005.

31. Allport VC, Slater DM, Newton R and Bennett PR: NF-kappaB and AP-1 are required for cyclo-oxygenase 2 gene expression in amnion epithelial cell line (WISH). Mol Hum Reprod 6: 561-565, 2000.

32. Benkoussa M, Brand C, Delmotte MH, Formstecher P and Lefebvre P: Retinoic acid receptors inhibit AP1 activation by regulating extracellular signalregulated kinase and CBP recruitment to an AP1-responsive promoter. Mol Cell Biol 22: 4522-4534, 2002.

33. Caelles C, Gonzalez-Sancho JM and Munoz A: Nuclear hormone receptor antagonism with AP-1 by inhibition of the JNK pathway. Genes Dev 11: 3351-3364, 1997.

34. Newton R, Stevens DA, Hart LA, Lindsay M, Adcock IM and Barnes PJ: Super-induction of COX-2 mRNA by cyclohexamide and interleukin-1beta involves increased transcription and correlates with increased NF-kappaB and JNK activation. FEBS Lett 418: 135-138, 1997.

35. Jang BC, Sung SH, Park JG, et al: Glucosamine hydrochloride specifically inhibits $\mathrm{COX}-2$ by preventing $\mathrm{COX}-2 \mathrm{~N}$-glycosylation and by increasing COX-2 protein turnover in a proteasomedependent manner. J Biol Chem 282: 27622-27632, 2007.

36. Nam SI: Interleukin-1beta up-regulates inducible nitric oxide by way of phosphoinositide 3-kinase-dependent in a cochlear cell model. Laryngoscope 116: 2166-2170, 2006.

37. Barnes PJ: How corticosteroids control inflammation: Quintiles Prize Lecture 2005. Br J Pharmacol 148: 245-254, 2006.

38. Bailey JM: New mechanisms for effects of anti-inflammatory glucocorticoids. Biofactors 3: 97-102, 1991.

39. Herr BD and Marzo SJ: Intratympanic steroid perfusion for refractory sudden sensorineural hearing loss. Otolaryngol Head Neck Surg 132: 527-531, 2005.

40. De Bosscher K, Van Craenenbroeck K, Meijer OC and Haegeman G: Selective transrepression versus transactivation mechanisms by glucocorticoid receptor modulators in stress and immune systems. Eur J Pharmacol 583: 290-302, 2008.

41. Newton R and Holden NS: Separating transrepression and transactivation: a distressing divorce for the glucocorticoid receptor? Mol Pharmacol 72: 799-809, 2007.

42. Ristimaki A, Garfinkel S, Wessendorf J, Maciag T and Hla T: Induction of cyclooxygenase-2 by interleukin-1 alpha. Evidence for post-transcriptional regulation. J Biol Chem 269: 11769-11775, 1994.

43. Jang BC, Sanchez T, Schaefers HJ, et al: Serum withdrawalinduced post-transcriptional stabilization of cyclooxygenase-2 mRNA in MDA-MB-231 mammary carcinoma cells requires the activity of the p38 stress-activated protein kinase. J Biol Chem 275: 39507-39515, 2000.

44. Park YK, Hong H and Jang BC: Transcriptional and translational regulation of COX-2 expression by cadmium in C6 glioma cells. Int J Mol Med 30: 960-966, 2012. 